\begin{tabular}{|c|l|}
\hline Title & Multifunctional sensing ability of a new Pt/Zn-based luminescent coordination polymer \\
\hline Author(s) & Kobay ashi, A tsushi; Hara, Hirofumi; Noro, Shin-ichiro; Kato, Masako \\
\hline Citation & $\begin{array}{l}\text { Dalton Transactions, 39144), 3400-3406 } \\
\text { https:/doi.org/10.1039/6917693d }\end{array}$ \\
\hline Issue Date & 2010-04_14 \\
\hline Doc URL & http://hdl.handle.net/2115/45233 \\
\hline Rights & Dalton Trans., 2010,39, 3400-3406- Reproduced by permission of The Royal Society of Chemistry (RSC) \\
\hline Type & article (author version) \\
\hline File Information & DT 39-14_3400-3406.pdf \\
\hline
\end{tabular}

Instructions for use 


\title{
Multifunctional Sensing Ability of a new Pt/Zn-Based Luminescent Coordination Polymer
}

\author{
Atsushi Kobayashi, ${ }^{a}{ }^{\text {Hirofumi Hara, }}{ }^{a}$ Shin-ichiro Noro ${ }^{\mathrm{b}}$ and Masako Kato* ${ }^{a}$ \\ Received (in XXX, XXX) Xth XXXXXXXXX 200X, Accepted Xth XXXXXXXXX 200X \\ ${ }_{5}$ First published on the web $X$ th $X X X X X X X X X 200 X$ \\ DOI: 10.1039/b000000x
}

We synthesized a new Pt/Zn-based coordination polymer, $\left\{\mathrm{Zn}\left[\mathrm{Pt}(\mathrm{CN})_{2}\left(5,5^{\prime} \text {-dcbpy }\right)\right] \cdot 4 \mathrm{H}_{2} \mathrm{O}\right\}_{\mathrm{n}}$, (5,5'- $\mathrm{H}_{2} \mathrm{dcbpy}=5,5^{\prime}$-dicarboxy-2,2'-bipyridine), which exhibits reversible colour changes in response to temperature change or exposure to chemical vapours and liquids. Such chromic

10 behaviour shows promise for sensing not only changes in temperature but also for detecting chemical solvents and vapours. The single crystal $\mathrm{X}$-ray structure indicates that one-dimensional coordination polymeric chains formed by an alternating arrangement of $\left[\mathrm{Zn}\left(\mathrm{H}_{2} \mathrm{O}\right)_{3}\right]^{2+}$ and $\left[\mathrm{Pt}(\mathrm{CN})_{2}\left(5,5^{\prime} \text {-dcbpy }\right)\right]^{2-}$ stacked to produce moderate metallophilic interactions between the $\mathrm{Pt}(\mathrm{II})$ ions. Thermogravimetric analysis and water vapour adsorption measurements show that both the 15 crystal water and water coordinated to Zn(II) ions can be removed and re-adsorbed reversibly by heating or under vacuum. Emission spectra at various temperatures and/or in the presence of vapours or liquids reveal that the complex exhibits thermochromic and solvatochromic-like behaviours, with the emission band shifting between 616 and $671 \mathrm{~nm}$. IR spectroscopy and powder $\mathrm{X}$-ray diffraction measurements suggest that this multichromic behaviour is a result of the 20 cooperative phenomena of water adsorption/desorption around the $\mathrm{Zn}(\mathrm{II})$ ions and the modification of the metallophilic interaction.

\section{Introduction}

Luminescent square-planar platinum(II)-diimine complexes have long attracted much attention owing to their interesting 25 optical properties. ${ }^{1-2}$ Some of the complexes exhibit bright phosphorescence from a triplet metal-to-ligand charge transfer $\left({ }^{3}\right.$ MLCT) transition state. ${ }^{1}$ In the case of one-dimensionally stacked Pt(II) complexes, the electronic interactions between $\mathrm{dz}^{2}$ orbitals of $\mathrm{Pt}(\mathrm{II})$ ions give rise to the metal-metal-to30 ligand charge transfer (MMLCT) emission state. ${ }^{2}$ The energy of the MMLCT state strongly depends on the distance between adjacent Pt ions. ${ }^{3}$ Thus, the colour and luminescence of these Pt(II) complexes are controllable by changing the metallophilic interaction between Pt ions. Recently, taking 35 advantage of this characteristic, some groups have reported the ability of $\mathrm{Pt}(\mathrm{II})$-diimine complexes to detect chemical vapours. ${ }^{4}$ This ability, the so-called 'electronic nose', is mainly based on the adsorption of vapour into the crystal lattice that induces significant change in the metallophilic 40 interaction. $^{5}$ As a result, the colour of the complex changes by exposure to chemical vapours; this is called as vapochromism. Most Pt(II)-diimine based vapochromic materials are composed of the $\mathrm{Pt}(\mathrm{II})$-polypyridine molecule, which acts as the chromophore, and interactions between these 45 chromophoric molecules are usually based on van der Waals interaction, hydrogen bonding and Coulombic interaction., These interactions give some flexibility to solid-state structures that enable them to recognize chemical vapours and change the structure accompanied by an adsorption of the 50 vapours. However, from the viewpoint of crystal engineering, these interactions make it difficult to control the structure and vapour selectivity.

Coordination polymers (CPs), on the other hand, have recently attracted increasing attention because of their 55 interesting gas adsorption capacity, controllable frameworks and other properties. ${ }^{6}$ It is well known that the framework of CPs can be controlled by substitution of the metal ion and bridging ligand; that is, the coordination geometry of the metal ion mainly determines the shape, and the bridging 60 ligand contributes to the size of the crystal lattice. ${ }^{7}$ This structural controllability may enable systematic control of both structure and vapour selectivity. Most CPs are insoluble in common solvents such as water, alcohols and hydrocarbons. Considering sensor durability, the insolubility of the sensing 65 material may result in high stability and reversible chromism of these sensing materials by preventing the elution and/or decomposition of the functional molecules. Therefore, with the aim of improving structural control of the vapochromic complexes and maintaining insolubility in solvents, we have 70 designed a new series of coordination polymers (CPs) based on the vapochromic $\mathrm{Pt}^{\mathrm{II}}$-diimine complex $\left[\mathrm{Pt}(\mathrm{CN})_{2}\left(4,4^{\prime}-\right.\right.$ $\mathrm{H}_{2}$ dcbpy)] (4,4'- $\mathrm{H}_{2} \mathrm{dcbpy}=4,4$ '-dicarboxy-2,2'-bipyridine) that can act as a complex ligand through two carboxylate groups. ${ }^{8}$ In this paper, we report the crystal structure, 75 adsorption properties and chromic behaviour of a newly synthesized Pt/Zn-based $\quad \mathrm{CP}, \quad\left\{\mathrm{Zn}\left[\mathrm{Pt}(\mathrm{CN})_{2}\left(5,5^{\prime}-\right.\right.\right.$ dcbpy)] $\left.4 \mathrm{H}_{2} \mathrm{O}\right\}_{\mathrm{n}} \quad\left(\mathbf{1} \cdot \mathbf{4} \mathbf{H}_{2} \mathbf{O} ;\right.$ 5,5'- $\mathrm{H}_{2}$ dcbpy = 5,5'-dicarboxy2,2'-bipyridine), and demonstrate that it exhibits reversible colour change in response to temperature change or exposure 80 to chemical vapours and liquids. The chromic behaviour of this CP makes it a promising material for multi-functional environmental sensor applications. 


\section{Results and Discussion}

Crystal structure. The reaction between $\left[\mathrm{Pt}(\mathrm{CN})_{2}\left(5,5^{\prime}-\right.\right.$ $\mathrm{H}_{2}$ dcbpy)] and $\mathrm{Zn}\left(\mathrm{NO}_{3}\right)_{2} \cdot 6 \mathrm{H}_{2} \mathrm{O}$ under basic conditions led to immediate formation of the insoluble coordination polymer $5 \mathbf{1} \cdot 4 \mathrm{H}_{2} \mathrm{O}$. This very fast reaction made it difficult to form single crystals of $\mathbf{1}$. Although most of the obtained crystals were very thin and twinned or polycrystalline, we successfully determined the crystal structure with enough quality by using a synchrotron light source (see Experimental). ${ }^{\ddagger}$ Figure 1 (a) 10 shows the structure of $\mathbf{1} \cdot 4 \mathrm{H}_{2} \mathrm{O}$ at $90 \mathrm{~K}$ viewed along the $b$ axis. Complex 1 crystallized in the monoclinic $P 2_{1} / m$ space group. The $\left[\mathrm{Pt}(\mathrm{CN})_{2}\left(5,5^{\prime} \text {-dcbpy) }\right]^{2-}\right.$ complex anion acts as a bridging ligand to produce an infinite 1-D linear polymeric chain along the $a+c$ axis (Figure 1(b)). None of the cyano groups of ${ }_{15}\left[\mathrm{Pt}(\mathrm{CN})_{2}\left(5,5^{\prime} \text {-dcbpy }\right)\right]^{2-}$ were directly bound to $\mathrm{Zn}$ ions. The $\mathrm{Zn}$ ion has a trigonal bipyramidal coordination structure with three water molecules in the equatorial plane and two carboxylate oxygens of the dcbpy ligand at the axial positions. The Pt-dcbpy units are uniformly stacked along the $b$ axis to 20 form a metallophilic interaction between adjacent Pt ions with 3.309(1) $\AA$ (Figure 1(c)). The distance between adjacent $\mathrm{Pt}$ ions observed for $\mathbf{1} \cdot 4 \mathrm{H}_{2} \mathrm{O}$ is longer than that of $\left[\mathrm{Pt}(\mathrm{CN})_{2}(4,4\right.$ '$\left.\left.\mathrm{H}_{2} \mathrm{dcbpy}\right)\right] \cdot 4 \mathrm{H}_{2} \mathrm{O}(3.2358(1) \AA)^{8}$, suggesting the existence of
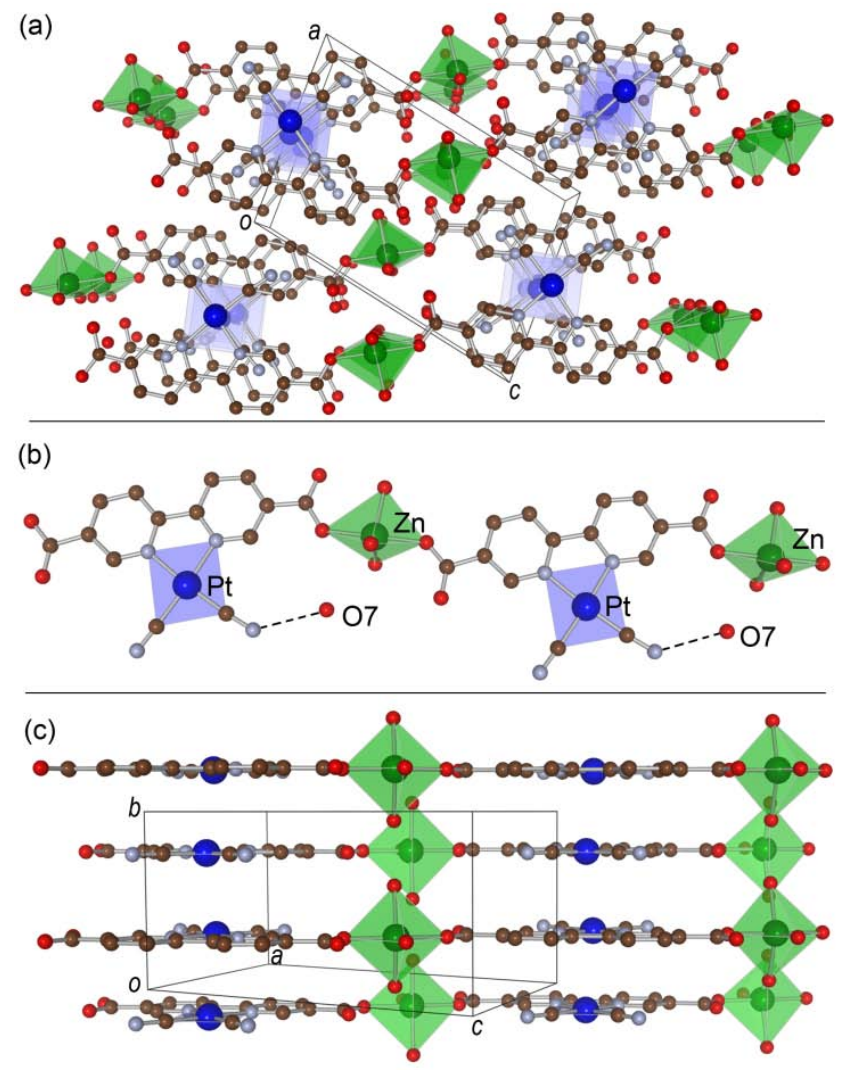

25 Fig. 1 (a) Perspective view of the unit cell of $\mathbf{1} \cdot 4 \mathrm{H}_{2} \mathrm{O}$ along $b$ axis. (b) One-dimensional chain structure of $\mathbf{1}$. Dotted lines show the hydrogen bonds. (c) Stacked structure with metallophilic interaction of 1. Pt, Zn, C, $\mathrm{N}$ and $\mathrm{O}$ atoms are indicated as blue, green, dark brown, light blue and red filled circles, respectively. Blue plates show the coordination

30 environments of $\mathrm{Pt}$, and green octahedrons show those of the $\mathrm{Zn}$ ions. $\mathrm{H}$ atoms are omitted for clarity. ${ }^{16}$ a weak metallophilic interaction in $\mathbf{1} \cdot 4 \mathrm{H}_{2} \mathrm{O}$. There are one crystallographically independent, non-coordinated water molecule (O7 atom) that was hydrogen bonded with the 35 coordinated water and the cyano group.

Water adsorption. As described in the Introduction, there are several vapochromic materials based on the $\mathrm{Pt}(\mathrm{II})$-diimine chromophore. ${ }^{4,5}$ In these complexes, the chromic behaviour usually originates from reversible changes in metallophilic 40 interactions induced by vapour adsorption. Our complex $\mathbf{1} \cdot 4 \mathrm{H}_{2} \mathrm{O}$ also shows a moderate metallophilic interaction and includes water molecules in the crystal structure, suggesting a possibility for chromic behaviour. To clarify the reversibility of water vapour adsorption and desorption, thermogravimetric 45 (TG) and differential thermal analyses (DTA) were performed. Figure 2 shows the TG-DTA plot of $\mathbf{1} \cdot 4 \mathrm{H}_{2} \mathrm{O}$. Upon heating, the sample weight gradually decreased, and two steep weight losses were observed at 345 (4.0\% loss) and $371 \mathrm{~K}(9.9 \%$ loss). These weight losses were close to the amounts of $2 \mathrm{H}_{2} \mathrm{O}$ $50(5.8 \%)$ and $4 \mathrm{H}_{2} \mathrm{O}(11.5 \%)$ in $\mathbf{1} \cdot 4 \mathrm{H}_{2} \mathrm{O}$, respectively. The small disagreement between the calculated and observed weight losses may be due to the partial desorption of water at room temperature. At the weight-loss temperatures, endothermic peaks were also observed. These results indicate that the

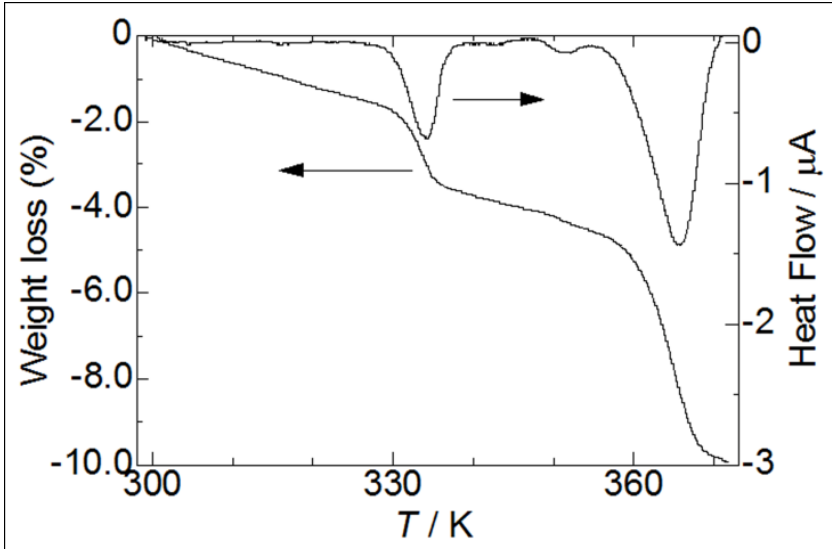

Fig. 2 TG-DTA curves of $\mathbf{1} \cdot 4 \mathrm{H}_{2} \mathrm{O}$. $(1 \mathrm{~K} / \mathrm{min}$ heating, Ar flow rate: 300 $\mathrm{ml} / \mathrm{min}$ )

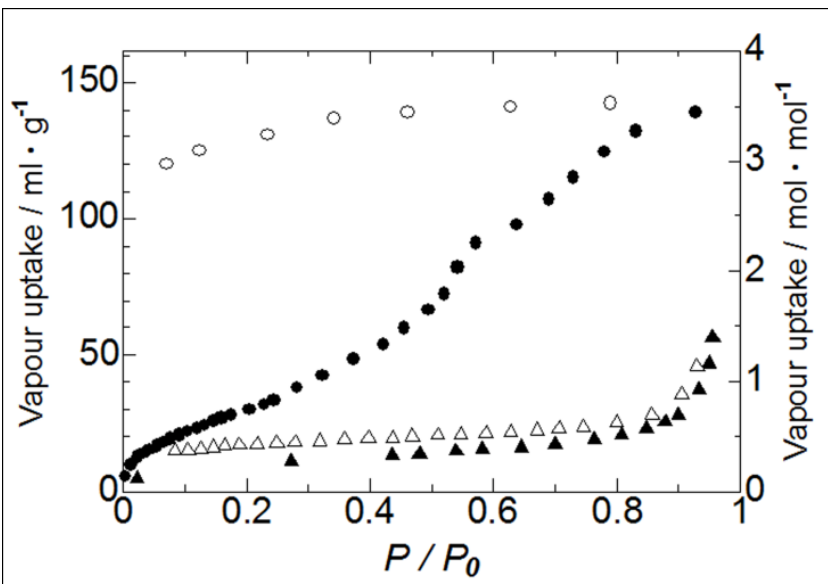

Fig. 3 Adsorption isotherms for water (circle) and methanol (triangle) vapour of 1 at $293 \mathrm{~K}$. The open and closed symbols represent the adsorption and desorption process, respectively. 
four water molecules included in $\mathbf{1} \cdot 4 \mathrm{H}_{2} \mathrm{O}$ could be removed easily by heating. The chemical compositions at 298, 343 and $373 \mathrm{~K}$, as estimated from the weight loss, represent approximately tetrahydrate $\mathbf{1} \cdot 4 \mathrm{H}_{2} \mathrm{O}$, dihydrate $\mathbf{1} \cdot 2 \mathrm{H}_{2} \mathrm{O}$ and 5 anhydrous $\mathbf{1}$, respectively. The adsorption isotherms of water and methanol vapour of $\mathbf{1}$ were measured (Figure 3). Before each measurement, the sample was heated at $373 \mathrm{~K}$ under vacuum to remove all crystal and coordinated water molecules. The dried complex 1 adsorbed water vapour at $3.5 \mathrm{~mol} \cdot \mathrm{mol}^{-1}$ 10 saturated amount, corresponding to the number of coordinated water molecules in $\mathbf{1} \cdot 4 \mathrm{H}_{2} \mathrm{O}$. The adsorption amount at the first step in the lower pressure region up to $P / P_{0}=0.57$ was approximately half the saturated amount $\left(\mathrm{ca} .2 \mathrm{~mol} \cdot \mathrm{mol}^{-1}\right)$. In the desorption process, the adsorption amount barely 15 decreased to $P / P_{0}=0.1$, suggesting that the adsorbed water molecules are tightly bound in the pores. This result is consistent with almost all water molecules being bound to $\mathrm{Zn}(\mathrm{II})$ ions. On the other hand, only a very small amount of physisorption was observed for methanol vapour. In addition, 20 note that 1 could not adsorb $\mathrm{N}_{2}$ gas, suggesting the lack of permanent porosity (Figure S1). This water vapour selective adsorption is related to either the window size of the pore or the coordination ability of the adsorbates.

Thermochromic behaviour driven by water vapour. It is 25 well known that some of the $\mathrm{Pt}(\mathrm{II})$-diimine complexes show bright emission from the triplet metal-metal-to-ligand charge transfer $\left({ }^{3} \mathrm{MMLCT}\right)$ state generated by the effective metallophilic interaction between $\mathrm{Pt}$ ions. ${ }^{3-5}$ Because the coordination polymer $\mathbf{1} \cdot 4 \mathrm{H}_{2} \mathrm{O}$ shows reversible water 30 adsorption/desorption and has effective metallophilic interaction, we examined the possibility of chromic behaviour.

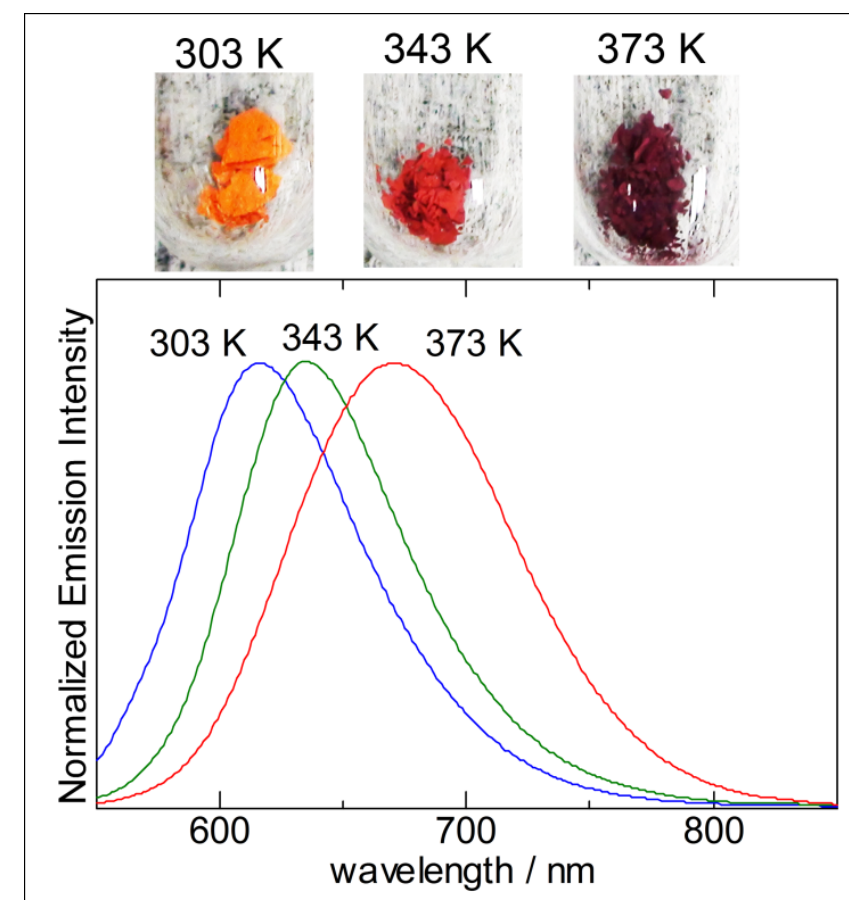

Fig. 4 (Top) Bright field images of 1 at 303, 343 and 373 K. (Bottom) Temperature dependence of the emission spectra of $1 . \lambda_{\mathrm{ex}} .=519 \mathrm{~nm}$.
${ }_{35}$ Figure 4 shows the temperature dependence of the emission spectra of $\mathbf{1}$. The emission maximum of $\mathbf{1} \cdot 4 \mathrm{H}_{2} \mathrm{O}$ was observed at $614 \mathrm{~nm}$ at $303 \mathrm{~K}$, that is, shorter by about $26 \mathrm{~nm}$ than that of $\left[\mathrm{Pt}(\mathrm{CN})_{2}\left(4,4^{\prime}-\mathrm{H}_{2} \mathrm{dcbpy}\right)\right] \cdot 4 \mathrm{H}_{2} \mathrm{O}(640 \mathrm{~nm}) .{ }^{8}$ This difference as discussed in the crystal structure section, suggesting that 40 the emission of $\mathbf{1} \cdot 4 \mathrm{H}_{2} \mathrm{O}$ is attributable to the ${ }^{3} \mathrm{MMLCT}$ state. Upon heating, the emission band shifted to a longer wavelength, up to 636 at $343 \mathrm{~K}$ and to $671 \mathrm{~nm}$ at $373 \mathrm{~K}$. In addition to the red shift of the emission band, the colour of the complex gradually changed from bright orange to red, and 45 finally, to dark purple (see Figure 4). The red shifts observed in emission spectra imply that the shrinkage of the Pt-Pt distance occurs upon heating. In addition, the emission band and colour reverted to the original colours when the temperature was lowered in humid air, indicating the 50 reversibility of the colour change, probably originates from the difference of the Pt-Pt distance.

To investigate the origin of thermochromism, powder X-ray diffraction (PXRD) patterns of $\mathbf{1} \cdot 4 \mathrm{H}_{2} \mathrm{O}$ were measured at various temperatures (Figure 5). The patterns observed at 305 55 and $343 \mathrm{~K}$ were almost identical to the simulation pattern calculated from the structure determined by single crystal Xray diffraction, showing that the structure of a dihydrate form $\mathbf{1} \cdot 2 \mathrm{H}_{2} \mathrm{O}$ is very similar to that of tetrahydrate $\mathbf{1} \cdot 4 \mathrm{H}_{2} \mathrm{O}$. On the other hand, the pattern at $373 \mathrm{~K}$, where 1 should be anhydrous, 60 was also similar to those at lower temperatures, but it should be noted that the 020 reflection observed at 20.73 deg. shifted about 0.3 deg to a higher angle. This result is evidence of the shrinkage of the crystal lattice along the $b$ axis, which corresponds to the direction of metallophilic interaction 65 between Pt ions. The observed shift of the 020 reflection to higher angle corresponds to the shortening of the Pt-Pt distance about $0.05 \AA$. Upon cooling to $305 \mathrm{~K}$ in humid air, the 020 reflection reverted to the original position as well as undergoing a colour change from dark purple to bright orange.

70 To obtain more detailed structural information about the thermochromism, the temperature dependence of IR spectrum

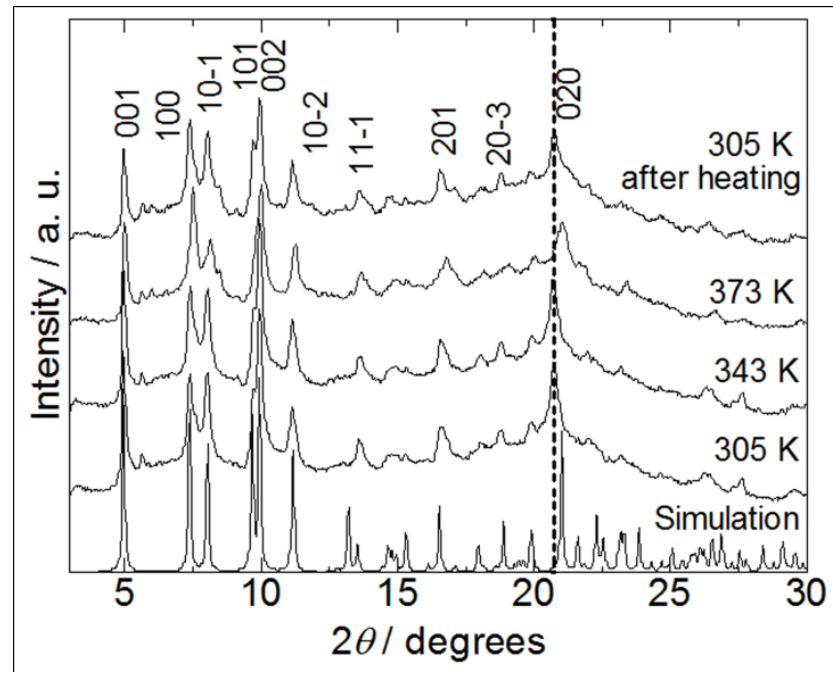

Fig. 5 Temperature dependence of PXRD patterns of $\mathbf{1}$. Indexes for main observed reflections are shown at the top. The pattern at the bottom is the 75 simulation calculated from the crystal structure of $\mathbf{1} \cdot 4 \mathrm{H}_{2} \mathrm{O}$ at $90 \mathrm{~K}$. The dotted line is drawn as a guide to the position of 020 reflection at $305 \mathrm{~K}$. 


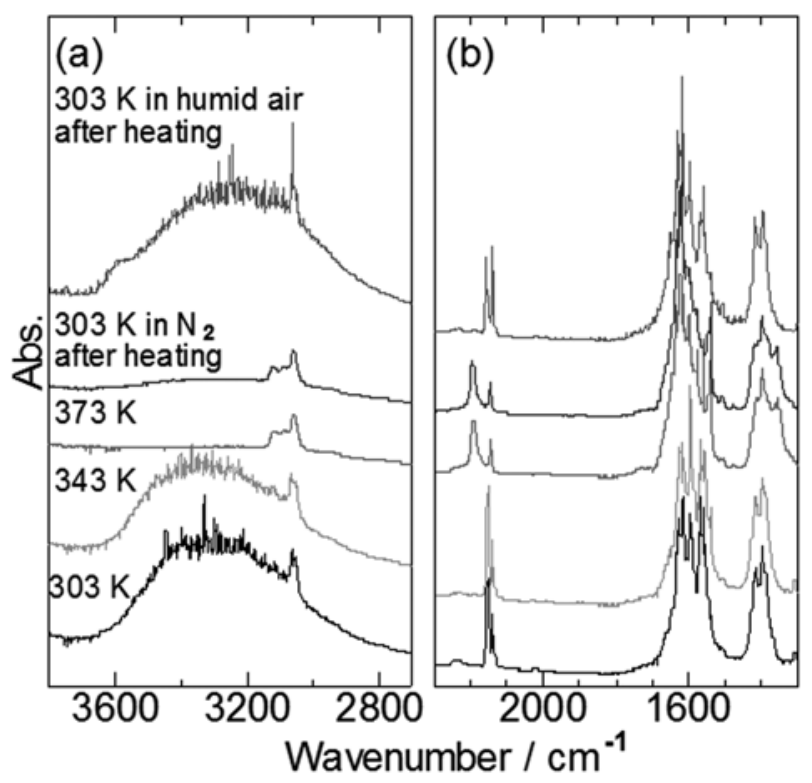

Fig. 6 Temperature dependence of IR spectrum of $\mathbf{1} \cdot 4 \mathrm{H}_{2} \mathrm{O}$. (a) Region of $\mathrm{O}-\mathrm{H}$ stretching mode in water. (b) Region of $\mathrm{CN}$ and $\mathrm{CO}$ stretching modes in cyanide ligand and carboxyl group.

5 of $1 \cdot 4 \mathrm{H}_{2} \mathrm{O}$ was measured (Figure 6). At $303 \mathrm{~K}$, the bands assignable to $\mathrm{O}-\mathrm{H}$ and $\mathrm{EN}$ stretching modes were observed at 3300 and $2150 \mathrm{~cm}^{-1}$, respectively. The main asymmetric and symmetric $\mathrm{C}=\mathrm{O}$ stretching modes were observed around 1596 and $1396 \mathrm{~cm}^{-1}$, respectively. The energy difference 10 between these two modes was about $200 \mathrm{~cm}^{-1}$, suggesting that the bonding mode of the carboxylate group is mainly monodentate. ${ }^{9}$ At $343 \mathrm{~K}$, where the complex changed from tetrahydrate to dihydrate, neither the IR spectrum nor the PXRD pattern changed significantly. On the other hand, above $15373 \mathrm{~K}$, several drastic changes were observed. The $\mathrm{O}-\mathrm{H}$ stretching mode disappeared, and theNCstretching mode was split into two peaks separated by about $50 \mathrm{~cm}^{-1}$, suggesting that all water molecules were removed from the crystal lattice and the cyano groups may coordinate to the $\mathrm{Zn}$ 20 ions in high temperature region. ${ }^{9}$ The $\mathrm{C}=\mathrm{O}$ bond stretching modes also changed with increasing temperature. The two bands of the asymmetric $\mathrm{C}=\mathrm{O}$ mode merged and shifted to lower energy at $1550 \mathrm{~cm}^{-1}$, and a new band at $1360 \mathrm{~cm}^{-1}$ appeared, which is lower than that of the symmetric $\mathrm{C}=\mathrm{O}$ 25 bond. These changes provide clear evidence of the remarkable changes in the coordination mode of the carboxy group. In other words, the coordination environments of $\mathrm{Zn}$ (II) ions dramatically changed at this temperature. From the viewpoint of the coordination environment of $\mathrm{Zn}$ (II) ions, the number of 30 coordinated atoms is five at $303 \mathrm{~K}$ (as discussed above). However, in anhydrous form 1, there are no water molecules in the framework, which may limit the number of coordination atoms to no more than six, likely, four. This structural transformation around the $\mathrm{Zn}(\mathrm{II})$ ions makes the metallophilic 35 interaction more effective, resulting in the red shift of the emission and the colour of complex 1. In addition, the spectrum at $373 \mathrm{~K}$ was not changed by lowering the temperature to $303 \mathrm{~K}$ in a dry nitrogen atmosphere, whereas it

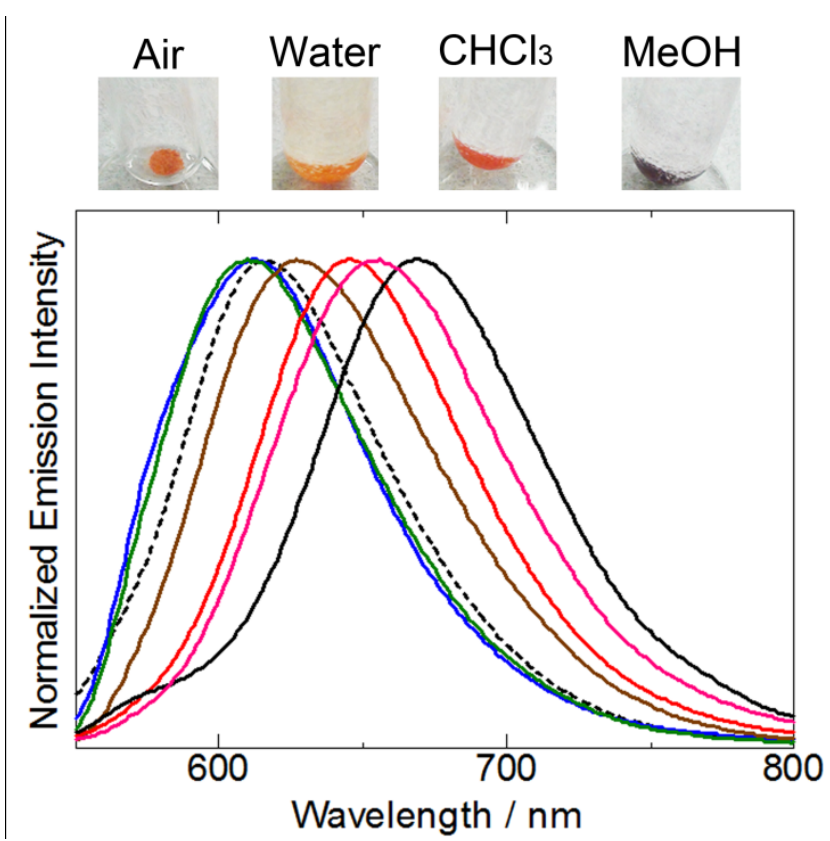

40 Fig. 7 Bright field images of $1 \cdot 4 \mathrm{H}_{2} \mathrm{O}$ in air, soaked in water, $\mathrm{CHCl}_{3}$ and $\mathrm{MeOH}$, respectively (top), and emission spectra of $\mathbf{1} \cdot 4 \mathrm{H}_{2} \mathrm{O}$ soaked in various liquid media at room temperature (bottom). $\lambda_{\text {ex }}=519 \mathrm{~nm}$. Dotted line shows the spectrum of $\mathbf{1} \cdot 4 \mathrm{H}_{2} \mathrm{O}$ in air. Blue, green, brown, red, purple and black solid lines show the spectra of the sample soaked in water,

45 hexane, benzene, ethanol, 1-pentanol, and DMF, respectively.

reverted to the spectrum at $303 \mathrm{~K}$ in humid air. These results indicate that water adsorption/desorption processes are key factors in the thermochromism of this complex.

Solvatochromic like behaviours in liquids. As described in the 50 Introduction, most vapochromic behaviours of Pt complexes occur based on a molecular assembly involving weak intermolecular interactions, such as hydrogen bonds or van der Waals interactions. ${ }^{5}$ Those weak interactions may enable these materials to undergo the structural change induced by 55 vapour adsorption. Our complex $1 \cdot 4 \mathrm{H}_{2} \mathrm{O}$ is composed of the polymeric chain formed by coordination bonds, which are stronger than hydrogen bonds. To examine whether the complex $1 \cdot 4 \mathrm{H}_{2} \mathrm{O}$ shows vapochromic behaviour, we measured the emission spectra under various conditions. Although the 60 colour of $\mathbf{1} \cdot 4 \mathrm{H}_{2} \mathrm{O}$ changed gradually when exposed to organic vapours, the corresponding changes occurred rapidly when the solid sample was immersed in the liquids. To estimate simply the effects of liquids, emission spectrum of $1 \cdot 4 \mathrm{H}_{2} \mathrm{O}$ was measured for the sample soaked in various liquid media. 65 Figure 7 shows the emission spectra of $\mathbf{1} \cdot 4 \mathrm{H}_{2} \mathrm{O}$ soaked in various liquids; the observed emission maxima of each spectrum are summarized in Table S1. The complex $1 \cdot 4 \mathrm{H}_{2} \mathrm{O}$ is essentially insoluble unless a strong base is added. The emission maximum of $\mathbf{1} \cdot 4 \mathrm{H}_{2} \mathrm{O}$ in air was observed at $614 \mathrm{~nm}$. 70 When $\mathbf{1} \cdot 4 \mathrm{H}_{2} \mathrm{O}$ was soaked in non-polar liquids such as hexane and toluene, the emission band barely changed, or slightly shifted to a longer wavelength (about $15 \mathrm{~nm}$ or less). Soaking $\mathbf{1} \cdot 4 \mathrm{H}_{2} \mathrm{O}$ in highly polar liquids shifted the emission band to a significantly longer wavelength, over $30 \mathrm{~nm}$, except in the 75 case of water. Along with the red shift of the emission band, 

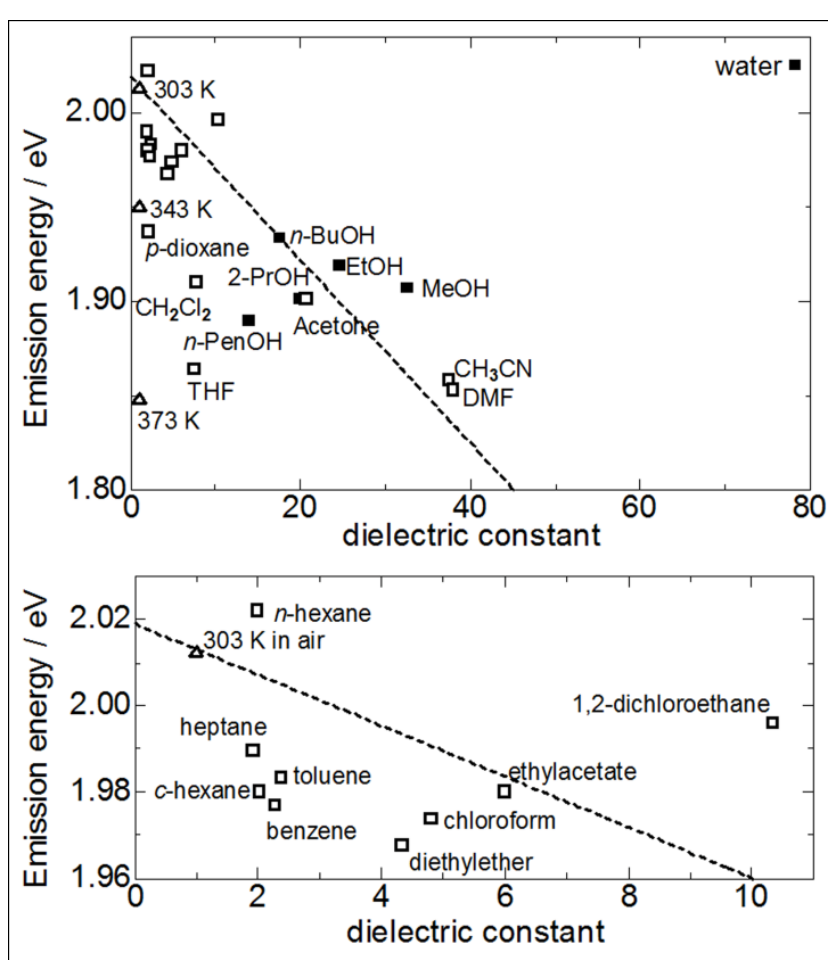

Fig. 8 Plot of the emission energy of $1 \cdot 4 \mathrm{H}_{2} \mathrm{O}$ against dielectric constant of the soaking liquid in all region (upper) and low dielectric constant region below 10 (lower). Data without liquid are shown as open triangles, and 5 with aprotic and protic liquids are shown as open and closed squares, respectively. The dotted lines are drawn as a guide.

the colour change from orange to dark purple induced by soaking is also very similar to that of the thermochromism (see images in Figure 7). As well as the red shifts observed in 10 emission spectra, the absorption band in diffusion reflectance spectrum of 1 shifted to longer wavelength about $100 \mathrm{~nm}$ when the sample was soaked in DMF (see Figure S3 in supporting information). It is noteworthy that the emission band also shifted to a longer wavelength in liquid $\mathrm{MeOH}$, in 15 spite of the lack of adsorbability for $\mathrm{MeOH}$. This result provides clear evidence showing that this solvatochromic-like behaviour originates from a structural transformation similar to that occurring in thermochromism. In fact, the emission band maximum of the sample soaked in DMF $(669 \mathrm{~nm})$ is 20 almost the same as that observed at $373 \mathrm{~K}(671 \mathrm{~nm})$. In addition, the emission energies seem to be proportional to the dielectric constant of the liquid as shown in Figure 8. The red shifts observed for THF, dichloromethane, and 1,4-dioxane are relatively larger than that for nonpolar liquids. THF and 25 dichloromethane have large dipole moments, 1.670 and 1.364 debye, respectively, which are close to that of $\mathrm{MeOH} .{ }^{10} 1,4-$ dioxane does not have a high dipole moment (about 0.002 debye) but has high affinity for water. ${ }^{10}$ It should be emphasised that these emission shifts in the soaking solvents 30 were hardly observed in the solvents that included $5 \%$ or more water (Figure S2). Considering these results, we believe that this solvatochromic-like behaviour originates from the elution of the water molecules involved in $\mathbf{1} \cdot 4 \mathrm{H}_{2} \mathrm{O}$ to liquid media, resulting in the red shift of emission with colour deepening.

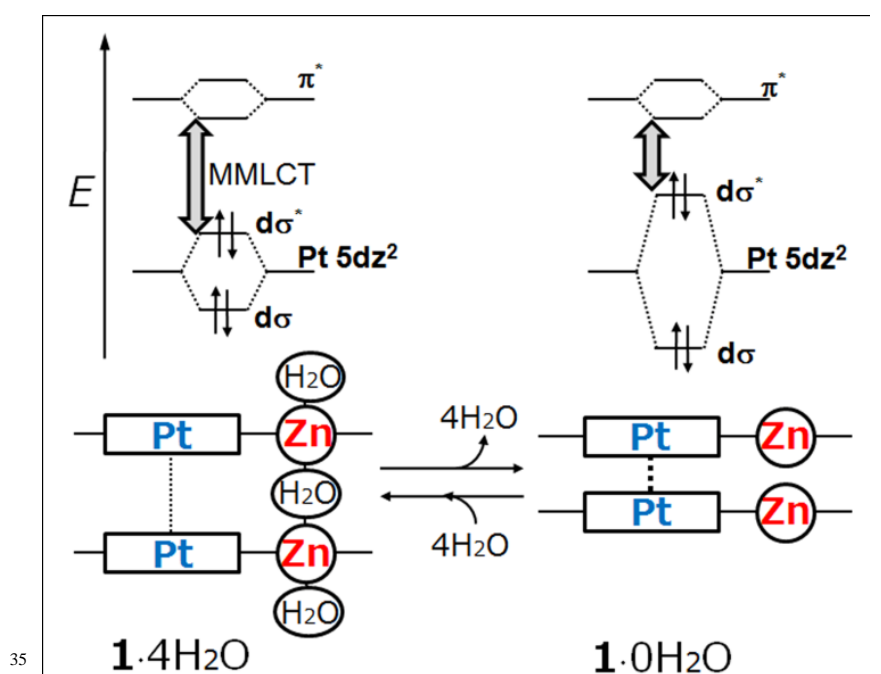

Scheme 1 Possible mechanism of the chromic behaviour of the complex 1. Upper and lower show schematic energy diagrams and structures of the two forms $\left(\mathbf{1} \cdot 4 \mathrm{H}_{2} \mathrm{O}\right.$ and $\left.\mathbf{1} \cdot 0 \mathrm{H}_{2} \mathrm{O}\right)$, respectively.

\section{Conclusion}

40 We have newly synthesised a Pt/Zn-based coordination polymer $\left\{\mathrm{Zn}\left[\mathrm{Pt}(\mathrm{CN})_{2}(5,5 \text { '-dcbpy) }] \cdot 4 \mathrm{H}_{2} \mathrm{O}\right\}_{\mathrm{n}}\right.$, and found that this polymer exhibits chromic behaviour under various environmental conditions. The structure of the polymer comprises onedimensional polymeric chains formed by alternating $\mathrm{Zn}(\mathrm{II})$ ${ }_{45}$ cations and $\left[\mathrm{Pt}(\mathrm{CN})_{2}\left(5,5^{\prime}-\mathrm{dcbpy}\right)\right]^{2-}$ complex anions. These chains are stacked to generate moderate metallophilic interaction between the Pt(II) ions. The temperature dependence shown by the powder X-ray diffraction and the IR spectrum reveal that the adsorption/desorption of water molecules coordinated to $\mathrm{Zn}$ (II) 50 ion is the main driving force of the chromic behaviour. The possible mechanism of the chromic behaviour of $\mathbf{1}$ is summarized in scheme 1 . The coordination geometry of $\mathrm{Zn}$ (II) strongly depends on the number of coordinated water molecules. As a result of changing the number of water molecules coordinated to 55 the $\mathrm{Zn}$ (II) ion, the metallophilic interaction between Pt ions changes simultaneously. In other words, the $\mathrm{Zn}(\mathrm{II})$ ions act as the water-adsorbing site and the $\mathrm{Pt}$ units serve as both the chromophore and emitting site. These chromic behaviours driven by water adsorption/desorption should be applicable to a 60 multifunctional environmental sensor that can sense temperature, pressure, humidity, chemical vapours, and liquids. Our preliminary experiments imply that the $\mathrm{Zn}(\mathrm{II})$ ion can be substituted by the other divalent metal ions, such as $\mathrm{Ca}$ (II) and $\mathrm{Ni}(\mathrm{II})$, and that the adsorption properties of these CPs seem to ${ }_{65}$ depend on the kind of the metal. Further work to develop a series of coordination polymers based on $\left[\mathrm{Pt}(\mathrm{CN})_{2}\left(5,5^{\prime} \text {-dcbpy) }\right]^{2-}\right.$ complex anion are now in progress.

\section{Experimental}

Syntheses. All starting materials, $\mathrm{K}_{2} \mathrm{PtCl}_{4}$ and 370 methylpyridine were used as received from commercial sources, and the solvents were used without any purification. $\mathrm{Pt}(\mathrm{CN})_{2},{ }^{11} 5,5^{\prime}-\mathrm{H}_{2} \mathrm{dcbpy}^{12}$ and $\left[\mathrm{Pt}(\mathrm{CN})_{2}\left(5,5^{\prime}-\mathrm{H}_{2} \mathrm{dcbpy}\right)\right]^{8}$ were 
prepared according to published methods. Elemental analysis was performed at the analysis centre in Hokkaido University.

$\left\{\mathrm{Zn}\left[\mathrm{Pt}(\mathrm{CN})_{2} \text { (5,5'-dcbpy) }\right] \cdot 4 \mathrm{H}_{2} \mathrm{O}\right\}_{\mathrm{n}} \quad\left(1 \cdot 4 \mathrm{H}_{2} \mathrm{O}\right): \quad \mathrm{KCl}$ saturated aqueous solution $(5 \mathrm{ml})$ was added to the solution of $5\left[\mathrm{Pt}(\mathrm{CN})_{2}\left(5,5^{\prime}-\mathrm{H}_{2} \mathrm{dcbpy}\right)\right](40 \mathrm{mg}, 82 \mu \mathrm{mol})$ in $0.1 \mathrm{M}$ aqueous ammonia $(8 \mathrm{mml})$. A yellow precipitate emerged immediately and was then filtered. The yellow precipitate was dissolved in water $(15 \mathrm{ml})$. To this clear yellow solution, the solution of $\mathrm{Zn}\left(\mathrm{NO}_{3}\right) \cdot 6 \mathrm{H}_{2} \mathrm{O}(24 \mathrm{mg}, 84 \mu \mathrm{mol})$ in water $(5 \mathrm{ml})$ was added.

${ }_{10}$ The orange precipitate immediately formed. After subsequent stirring for $1 \mathrm{~h}$ at room temperature, the solids were filtered off from the reaction mixture. The isolated precipitate was washed thoroughly with water and then dried in air for 1 day to afford orange powder $1.4 \mathrm{H}_{2} \mathrm{O}(42 \mathrm{mg}, 67 \mu \mathrm{mol})$ in $82 \%$ 15 yield. A single crystal suitable for $\mathrm{X}$-ray structural determination of $\mathbf{1} \cdot 4 \mathrm{H}_{2} \mathrm{O}$ was obtained by the diffusion method of water/EtOH with ethyl acetate as an intermediate buffer at $323 \mathrm{~K}$. Elemental analysis calcd. for $\mathrm{C}_{14} \mathrm{H}_{6} \mathrm{~N}_{4} \mathrm{O}_{4} \mathrm{PtZn} \cdot 4 \mathrm{H}_{2} \mathrm{O}$ : C 26.83, $\mathrm{H}$ 2.25, N 8.94; found: C 20 26.59, H 2.31, N 8.70.

Single crystal $X$-ray structural determination. Single crystal X-ray diffraction measurement was performed using a Rigaku MERCURY CCD diffractometer at NW2A beamline of the Advanced Ring, Photon Factory of KEK, Japan. The 25 wavelength of the synchrotron X-ray was $0.6890(1) \AA$. A single crystal of $1.4 \mathrm{H}_{2} \mathrm{O}$ (crystal dimension: $0.20 \times 0.04 \times$ $0.02 \mathrm{~mm}^{3}$ ) was mounted on a MicroMount with paraffin oil. A nitrogen gas flow temperature controller was used to cool the sample at $90 \mathrm{~K}$. Diffraction data were collected using ${ }_{30}$ CrystalClear $^{13}$ and processed by HKL2000. ${ }^{14}$ The structure was solved by a direct method using SIR2004 and refined by the full-matrix least-squares using SHELXL97. ${ }^{15}$ The nonhydrogen atoms were refined anisotropically. $\mathrm{H}$ atoms were refined using the riding model.

35 Powder X-ray diffraction. Powder X-ray diffraction measurements at various temperatures were performed using a Rigaku SPD diffractometer at beamline BL-8B, Photon Factory, KEK, Japan. The wavelength of the synchrotron Xray was $1.200(1) \AA$. The sample was placed in a glass 40 capillary of $0.5 \mathrm{~mm} \phi$ diameter. The temperature of the sample was controlled using a nitrogen gas flow variable temperature controller.

Luminescence spectroscopy. Emission and excitation spectra were recorded under various conditions on a Jasco FP-6600

45 spectrofluorometer. The sample temperature was controlled by a JASCO ETC-273 peltier-type temperature controller. About $1 \mathrm{mg}$ of the sample was placed in a glass capillary of $0.5 \mathrm{~mm} \phi$ in diameter. Slit widths of exicitation and emission light are 5 and $6 \mathrm{~nm}$, respectively.

${ }_{50}$ IR spectroscopy. Temperature-dependent IR spectra were recorded on a Nicolet 6700 FT-IR spectrometer using a Nicolet Continuum microscope. The sample temperature was controlled by a Linkam LK-600 hotstage.

Thermogravimetric analysis. Thermogravimetry and ${ }_{55}$ differential thermal analysis were performed using a Rigaku ThermoEvo TG8120 analyzer.

Adsorption Isotherms. The adsorption isotherms of water and $\mathrm{MeOH}$ vapours at $293 \mathrm{~K}$ were performed using an automatic volumetric adsorption apparatus (BELSORP MAX; BEL Japan, 60 Inc.)

\section{Acknowledgements}

We thank Dr. A. Nakao (KEK-PF) and Prof. T. Ozeki (Tokyo Inst. Tech.) for their kind experimental support and helpful 65 discussion. This work is supported by a Grant-in-Aid for Scientific Research, Photochromism (No.471), Young Scientists (B) (19750050) and the Global COE Program (Project No. B01: Catalysis as the Basis for Innovation in Materials Science) from MEXT, Japan.

\section{${ }_{70}$ Notes and references}

${ }^{a}$ Division of Chemistry, Faculty of Science, Hokkaido University, North10 West-8, Kita-ku, Sapporo 060-0810, Japan. Fax: 81-11-706-3447; Tel:81-11-706-3817; E-mail: akoba@sci.hokudai.ac.jp (A.K.), mkato@sci.hokudai.ac.jp (M. K.)

$75{ }^{b}$ Research Institute for Electronic Science, Hokkaido University, North20, West-10, Kita-ku, Sapporo 001-0020, Japan

$\dagger$ Electronic Supplementary Information (ESI) available: Adsorption isotherms for $\mathrm{N}_{2}$ at $77 \mathrm{~K}$, emission spectrum in acetonitrile containing $5 \%$ water, diffusion reflectance spectra and the relationship between emission

80 maxima, luminescent quantum efficiencies and dielectric constants of the liquids. See DOI: 10.1039/b000000x/

$\ddagger$ Crystal data of $\mathbf{1} \cdot \mathbf{4 H}_{2} \mathbf{O}:\left\{\mathrm{Zn}\left[\mathrm{Pt}(\mathrm{CN})_{2}\left(5,5^{\prime} \text {-dcbpy) }\right] \cdot 4 \mathrm{H}_{2} \mathrm{O}\right\}_{\mathrm{n}}, T=90(1) \mathrm{K}\right.$, $P 2_{1} / m$ (\#11), $a=9.495(17) \AA, b=6.577(11) \AA, c=14.10(2) \AA, \beta=$ 101.38(3) $)^{\circ}, V=864(3) \AA^{3}, Z=2, \mu(\mathrm{MoK} \alpha)=7.6 \mathrm{~mm}^{-1}, D_{\text {calc. }}=2.410$ $85 \mathrm{~g} \cdot \mathrm{cm}^{-3}, R_{\text {int }}=0.112$. No. of collected and unique reflections were 9503 and 3055, respectively. The final $R_{1}$ and $w R\left(F^{2}\right)$ were 0.0780 and $0.2296(I>$ $2 \sigma$ ), respectively. Full Crystallographic details have been deposited with Cambridge Crystalloigraphic Data Centre as supplementary publication No. CCDC-744577.

901 T. W. Thomas and A. E. Underhill, Chem. Soc. Rev., 1972, 1, 99; V. H. Houlding and V. M. Miskowski, Coord. Chem. Rev., 1991, 111, 145; C.-M. Che, L.-Y. He, C.-K. Poon and T. C. W. Mak, Inorg. Chem., 1989, 28, 3081; V. M. Miskowski and V. H. Houlding, Inorg. Chem., 1989, 28, 1529; L. Chassot, E. Muller, A. V. Zelewsky, Inorg. Chem., 1984, 23, 4249-4253; R. Ballardini, G. Varani, M. T. Indelli and F. Scandola, Inorg. Chem., 1986, 25, 3858; J. A. Zuleta, M. S. Burberry and R. Eisenberg, Coord. Chem. Rev., 1990, 97, 47.; J. Zhang, P. Du, J. Schneider, P. Jarosz, R. Eisenberg, J. Am. Chem. Soc., 2007, 129, 7726.; S. Huertas, M. Hissler, J. E. McGarrah, R. J. Lachicotte and R. Eisenberg, Inorg. Chem., 2001, 40, 1183.; S. D. Cummings and R. Eisenberg, J. Am. Chem. Soc., 1996, 116, 1949.; M. Kato, Y. Shishido, Y. Ishida and S. Kishi, Chem. Lett., 2008, 37, 16.; A. Islam, H. Sugihara, K. Hara, L. P. Singh, R. Katoh, M. Yanagida, Y. Takahashi, S. Murata, H. Arakawa, G. Fujihashi, Inorg. Chem., 2001, 40, 5371.

2 J. A. Bailey, M. G. Hill, R. E. Marsh, V. M. Miskowski, W. P. Schaefer and H. B. Gray, Inorg. Chem., 1995, 34, 4591.; A. Y.-Y. Tam, K. M.-C. Wong, G. Wang and V. W.-W. Yam, Chem. Commun., 2007, 2028.; V. W.-W. Yam, K. M.-C. Wong and N. Zhu, 110 J. Am. Chem. Soc., 2002, 124, 6506.; V. W.-W. Yam, K. H.-Y. Chan, K. M.-C. Wong and N. Zhu, Chem. Eur. J., 2005, 11, 45354543.; S.-Y. Lai, H.-W. Lam, W. Lu, K.-K. Cheung and C.-M. Che, Organometallics, 2002, 21, 226.;

3 W. B. Connick, L. M. Henling, R. E. Marsh and H. B. Gray, Inorg. 115 Chem., 1996, 35, 6261.; M. Kato, C. Kosuge, K. Morii, J. S. Ahn, H. Kitagawa, T. Mitani, M. Matsushita, T. Kato, S. Yano and M. Kimura, Inorg. Chem., 1999, 38, 1638.; B. Ma, J. Li, P. I. Djurovich, M. Yousufuddin, R. Bau and M. E. Thompson, J. Am. Chem. Soc., 2005, 127, 28.

1204 C. L. Exstrom, J. R. Sowa, C. A. Daws, D. Janzen, K. R. Mann, Chem. Mater. 1995, 7, 15; M. Albrecht, M. Lutz, A. L. Spek, G. Koten, Nature, 2000, 406, 970; M. H. Keefe, K. D. Benkstein, J. T. 
Hupp, Coord. Chem. Rev., 2000, 205, 201; S. M. Drew, D. E. Janzen, C. E. Buss, D. I. MacEwan, K. M. Dublin, K. R. Mann, J. Am. Chem. Soc. 2001, 123, 8414; T. J. Wadas, Q.-M Wang, Y.-J. Kim, C. Flaschenreim, T. N. Blanton, R. Eisenberg, J. Am. Chem. 5 Soc. 2004, 126, 16841; L. J. Grove, J. M. Rennekamp, H. Jude, W. B. Connick, J. Am. Chem. Soc. 2004, 126, 1594; J. Fornies, S. Fuertes, J. A. Lopez, A. Martin, V. Sicilia, Inorg. Chem., 2008, 47, 7188; M. L. Muro, C. A. Daws, F. N. Castellano, Chem. Commun., 2008, 6134; S. C. F. Kui, S. S.-Y. Chui, C.-M. Che, N. Zhu, J. Am. Chem. Soc. 2006, 128, 8297; M. Kato, Bull. Chem. Soc. Jpn. 2007, 80, 287.

5 J. Fornies, S. Fuertes, J. A. Lopez, A. Martin and V. Sicilia, Inorg. Chem., 2008, 47, 7166; S. Kishi and M. Kato, Mol. Cryst. Liq. Cryst., 2002, 379, 303.; M. Kato, A. Omura, A. Toshikawa, S. Kishi and Y. Sugimoto, Angew, Chem. Int. Ed., 2002, 41, 3183.

6 M. D. Allendorf, C. A. Bauer, R. K. Bhakta and R. J. T. Houk, Chem. Rev. Soc. 2009, 38, 1330-1352; S. Kitagawa, R. Kitaura and S. Noro, Angew. Chem. Int. Ed., 2004, 43, 2235; H. Li, M. Eddaoudi, M. O’Keeffe and O. M. Yaghi, Nature, 1999, 402, 276; N. L. Rosi, J. Eckert, M. Eddaoudi, D. T. Vodak, J. Kim, M. O’Keeffe, O. M. Yaghi, Science, 2003, 300, 1127; N. L. Rosi, J. Kim, M. Eddaoudi, B. Chem, M. O’Keeffe, O. M. Yaghi, J. Am. Chem. Soc. 2005, 127, 1504; R. Matsuda, R. Kitaura, S. Kitagawa, Y. Kubota, R. V. Belosludov, T. C. Kobayashi, H. Sakamoto, T. Chiba, M. Takata, Y. $25 \quad$ Kawazoe and Y. Mita, Nature, 2005, 436, 238; O. M. Yaghi, M. O’Keeffe, N. Ockwig, H. K. Chae, M. Eddaoudi, J. Kim, Nature, 2003, 423, 705.

7 R. Kitaura, G. Onoyama, H. Sakamoto, R. Matsuda, S. Noro and S. Kitagawa, Angew. Chem. Int. Ed. 2004, 43, 2684; S. Noro, S.

$30 \quad$ Kitagawa, M. Yamashita and T. Wada, Chem. Commun. 2002, 222; K. C. Szeto, C. Prestipino, C. Lamberti, A. Zecchina, S. Bordiga, M. Bjrgen, M. Tilset and K. P. Lillerud, Chem. Mater., 2007, 19, 211; J. Hafizovic, U. Olsbye, K. P. Lillerud, Acta. Cryst., 2007, E63, m962; C. Mulcahy, F. M. Dolgushin, K. A. Krot, D. Griffith and C. J.

35 Marmion, Dalton Trans., 2005, 1993; K. C. Szeto, K. P. Lillerud, M. Tilset, M. Bjrgen, C. Prestipino, A. Zecchina, C. Lamberti and S. Bordiga, J. Phys. Chem. B, 2006, 110, 21509.

8 M. Kato, S. Kishi, Y. Wakamatsu, Y. Sugi, Y. Osamura and T. Koshiyama, M. Hasegawa, Chem. Lett., 2005, 34, 1368.

409 X. Hung, S. Jiang and M. Liu, J. Phys. Chem. B, 2005, 109; C. Ohe, H. Ando, N. Sato, Y. Urai, M. Yamamoto, K. Itoh, J. Phys. Chem. B, 1999, 103, 435; K. Nakamoto, Infrared and Raman Spectra of Inorganic and Coordination Compounds, 4th ed.; Wiley: New York, 1986; p 232.

4510 N. Hirota, in Handbook of Chemistry, ed. K. Hatake, Maruzen, Tokyo, Basic $4^{\text {th }}$ Ed. 1984, Vol. 2, ch. 13, pp. 501-506.

11 A. Avshu and A. M. Parkins, J. Chem. Research, 1984, 2201-2209.

12 K. C. Szeto, K. O. Kongshaug, S. Jakobsen, M. Tilset, K. O. Lillerud, Dalton Trans., 2008, 2054-2060; H. F.M. Nelissen, M. C. Feiters, R.

$50 \quad$ J. M. Nolte, J. Org. Chem., 2002, 67, 5901.

13 CrystalClear; Molecular Structure Corporation: Orem, UT, 2001.

14 Z. Otwinowski and W. Minor, Methods Enzymol., 1997, 276A, 307.

15 SIR2004; M. C. Burla, R. Caliandro, M. Camalli, B. Carrozzini, G. L. Cascarano, L. De Caro, C. Giacovazzo, G. Polidori, and R. Spagana,

$55 \quad$ J. Appl. Cryst., 2005, 38, 381; SHLEX97; G. M. Sheldrick, Acta Crystallogr., Sect. A, 2008, 64, 112.

16 These pictures were drawn by VESTA computer program. K. Momma and F. Izumi, "VESTA: a three-dimensional visualization system for electronic and structural analysis,” J. Appl. Crystallogr., 2008, 41, 653. 